\title{
Aortopulmonary Window. Clinical and Surgical Assessment of 18 Cases
}

\author{
Andressa Mussi Soares, Edmar Atik, Tâmara Martins Cortêz, Angela Maria T. Albuquerque, \\ Claudia P. Castro, Miguel Barbero-Marcial, Munir Ebaid
}

\author{
São Paulo, SP - Brazil
}

\begin{abstract}
Objective - Aortopulmonary window (APW) is an uncommon congenital malformation. Its clinical presentation is dependent on the size of the defect and on the associated lesions. We evaluated our experience with this anomaly and compared it with 296 cases reported in the literature.

Methods - Retrospective study of 18 patients diagnosed as having $A P W$ (age range from 13 days to 31 years, 13 (72.2\%) females), divided into two groups: Group $A(G A)$ : 10 patients with isolated $A P W$, and Group B $(G B): 8$ patients with associated lesions.
\end{abstract}

Results - Heart failure occurred in 14 patients, and cyanosis in 3: 2 from GB (tetralogy of Fallot-TF, and double outlet right ventricle-DORV), and one from $G A$ with pulmonary hypertension. In 5 patients from $G A$ the diagnosis of mitral regurgitation was made based on a systolic murmur and $L V$ hypertrophy on the EKG. In GB, clinical findings were determined by the associated defect. Diagnosis was established by echocardiography in 11 (61.2\%) of the patients. In 3 patients, a wrong diagnosis of mitral regurgitation was made, in 1 a patent ductus arteriosus was diagnosed and in 3 others, the diagnosis of APW was masked by other important associated defects ( 2 cases of DORV and 1 case of TF). The diagnosis was made by catheterization in 3 (16.6\%) patients, by surgery in $3(16.6 \%)$ and by necropsy in $1(5.5 \%)$. Corrective surgery was performed in 14 (77.7\%) patients, with one immediate death and good longterm follow-up in the remaining patients.

Conclusion - APW can be confused with other defects. Clinical findings, associated with an adequate echocardiogram can provide the information for the correct diagnosis.

Keywords: aortopulmonary window, diagnosis, and cardiac surgery

Instituto do Coração do Hospital das Clínicas - FMUSP

Mailing address: Edmar Atik - Incor - Av. Dr. Enéas C. Aguiar, 44 - 05403-000

- São Paulo, SP - Brazil
Aortopulmonary window is an uncommon anomaly, occurring in less than $1 \%$ of all persons with a congenital heart disease. It consists of a communication between the ascending aorta and the pulmonary trunk and/or the right pulmonary artery. It has similar hemodynamic features to a patent ductus arteriosus (PDA) or, even more so, to a common truncus arteriosus (CTA), the anatomical difference from the latter being the presence of well-defined aortic and pulmonary valve apparatus.

John Elliotson first described it in $1830^{1}$ and Gross performed the first successful surgery in $1948^{2}$.

Didactic classifications were done by Mori in $1978^{3}$ and by Richardson, in $1979^{4}$, with some variations between the two. Mori's classification, which is more used, is shown in figure 1. Type I, or proximal: the communication is usually rounded and located above the semilunar valves, between the ascending aorta and the pulmonary trunk. Type II, or distal: the defect, in a spiral curve, involves the pulmonary bifurcation at the level of the right pulmonary artery (RPA). In this type of defect, there can be hypoplasia or even aortic arch interruption due to the significant deviated flow from the aorta towards the RPA during fetal life. Type III is characterized by total absence of the aortopulmonary septum resulting from the combination of proximal and distal defects, simulating a CTA.

In a review of the literature ${ }^{1,5-18}$, we found 296 published cases of APW and we than decided to review our own data.

\section{Methods}

Eighteen patients were diagnosed as having APW in a 12-year period (from 1986 to 1998) at our institution. Age at the time the diagnosis was made ranged from 13 days to 31 years, and the majority of patients $(70.1 \%)$ were young infants (mean age: 8 months). Thirteen $(72.2 \%$ ) were females.

Ten patients had isolated APW (GB, table I). Clinical aspects, such as signs of heart failure and/or hypoxia, were analyzed in order to establish the diagnosis together with complementary tests (chest X-ray, electrocardiogram) and, specially, the echocardiogram and the hemodynamic study. Surgical and follow-up features have also been assessed. 


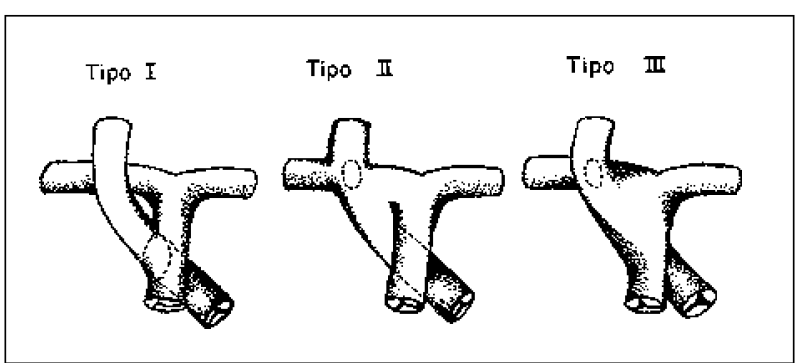

Fig. 1 - Schematic drawing of the anatomical types of aortopulmonary window Type: I- proximal defect; Type II- distal defect; Type III- complete defect (I + II). (Adapted from Mori $\mathrm{Ket} \mathrm{al}^{3}$ ).

\section{Results}

Clinical Aspects: Early and severe heart failure developed in 11 infants (mean age 35 days of life) and later on in three patients, with a mean age of 8 years. Cardiogenic shock, unresponsive to the use of prostaglandin, vasoactive drugs and inotropics, occurred in a newborn presenting with APW associated with aortic valve atresia and aortic arch interruption. Cyanosis was present in three patients; two of the three had associated defects (TF in one, DORV with a ventricular septal defect in the other) and one had high pulmonary vascular resistance. A characteristic murmur for APW could not be detected in any of these patients. Five patients in GA (50\%) had signs suggestive of mitral regurgitation and a soft systolic murmur was detected in the left parasternal border of five patients (50\%). A protosystolic click could be heard in the high left parasternal border of two of these patients. In GB patients, auscultation was as expected for the associated defect (TF, DORV, aortic coarctation - CoAo-, PDA, ventricular septal defect-VSD-, subaortic stenosis).

\begin{tabular}{|l} 
Table I - Aortopulmonary window isolated and associated with other \\
defects. Anatomical aspects
\end{tabular}

Chest X-ray: Moderate-to-severe increase in heart size, due to left atrial and ventricular enlargement, together with increased pulmonary vessels were found in $8(80 \%)$ of GA patients. A distinct egg-shaped heart silhouette was present. In GB patients, chest X-ray was as expected for the associated defect (fig. 2).

Electrocardiogram: Biventricular hypertrophy was the dominant finding, occurring in 11 patients, followed by left ventricular hypertrophy in 6 patients, equally distributed in both groups. Isolated right ventricular hypertrophy was present in the patient presenting with high pulmonary vascular resistance. Right bundle branch block, atrial fibrillation, and left anterior hemiblock could be detected in three patients, all of them having associated cardiac defects

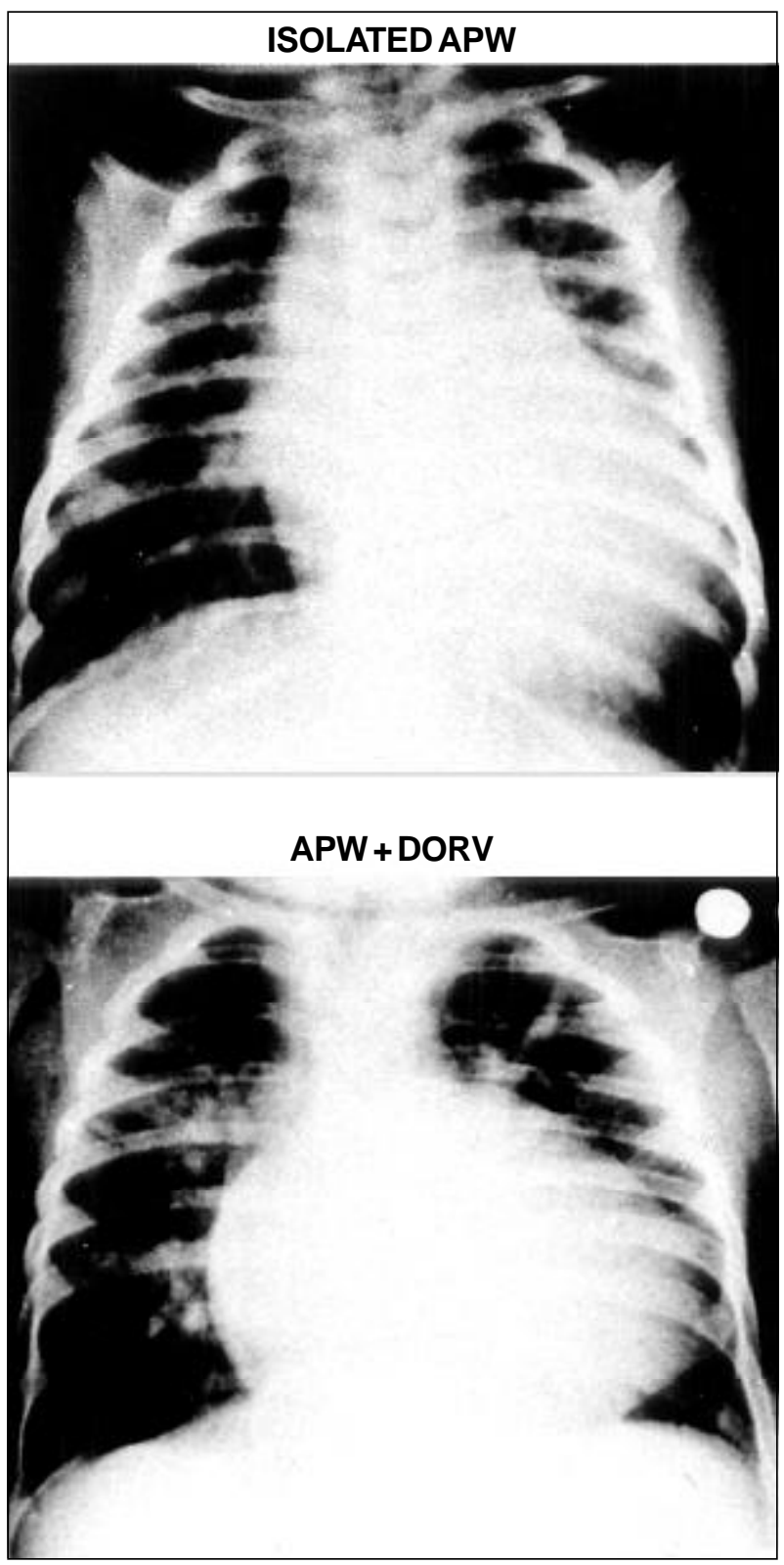

Fig. 2 - Chest X-rays comparing cardiac silhouette in isolated aortopulmonary window (group A) and in the presence of associated defects (group B - double outlet right ventricle). 
(VSD, subaortic stenosis and aortic valve atresia with aortic arch interruption, respectively).

Echocardiogram: The diagnosis of APW was made with Dopplerechocardiography with color flow mapping in 10 patients, 6 from GA and 4 from GB. In one patient with a fixed subaortic stenosis, the diagnosis was made by preoperative transesophageal echocardiogram (table II).

The four cases in which the echocardiogram failed to diagnose the APW were mistakenly diagnosed as mitral regurgitation (three patients) and PDA (one patient). APW was not detected in one patient with TF and in two patients with DORV. Type I APW was diagnosed in nine patients (fig. 3) and type II in 2 (fig. 4).

Hemodynamic Study: Seven patients underwent an invasive hemodynamic study (3 in GA and 4 in GB) (fig. 5). The diagnosis of APW was made in one infant who had previously been diagnosed by echocardiogram as having a PDA, and in two other patients (one with TF and one with a noncommitted VSD). The echocardiographic diagnosis was confirmed in two GB patients and in one GA patient.

A wrong diagnosis of CTA was made on angiography in one newborn, who had been correctly diagnosed by echocardiogram as having APW associated with aortic valve atresia and aortic arch interruption.

Intraoperative Diagnosis: In three patients, the correct diagnosis was made at surgery. The first patient had DORV and an associated subaortic VSD (this patient hadn't undergone cardiac catheterization). Another infant was sent to surgery with the diagnosis of congenital mitral regurgitation. At surgery, this patient was found to have a 20-mm APW with a very dilated left atrium and severe mitral regurgitation due to dilation of the mitral ring. The third patient, a 13-year-old girl, had been diagnosed as having rheumatic mitral disease and a subaortic stenosis. At surgery, she was found to have a 22-mm APW associated with an anomalous right coronary artery arising from the

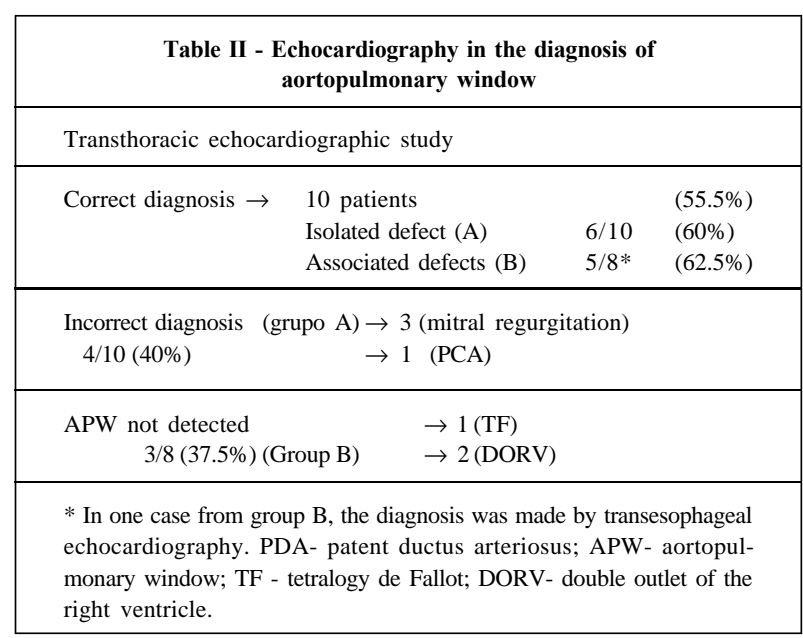

right pulmonary artery. Mitral valve was anatomically normal (table III).

Necropsy: One infant, with the clinical diagnosis of congenital mitral regurgitation, with heart failure and associated bronchopneumonia, was found at necropsy to have APW (table III).

Surgical findings: Fourteen patients underwent surgery (six with isolated APW and eight with associated defects) and one patient with associated defects died intraoperatively.

A proximal communication (type I) was present in 12 patients $(85.7 \%)$ of the 14 who underwent surgery, while in two (14.3\%), a communication between the ascending aorta and the RPA (type II defect) was present. The size of the defect ranged from 10 to $22 \mathrm{~mm}$. Cardiopulmonary bypass and hypothermia were used in all patients. Surgical approach was through an aortotomy, with closure of the APW using a bovine pericardium patch.

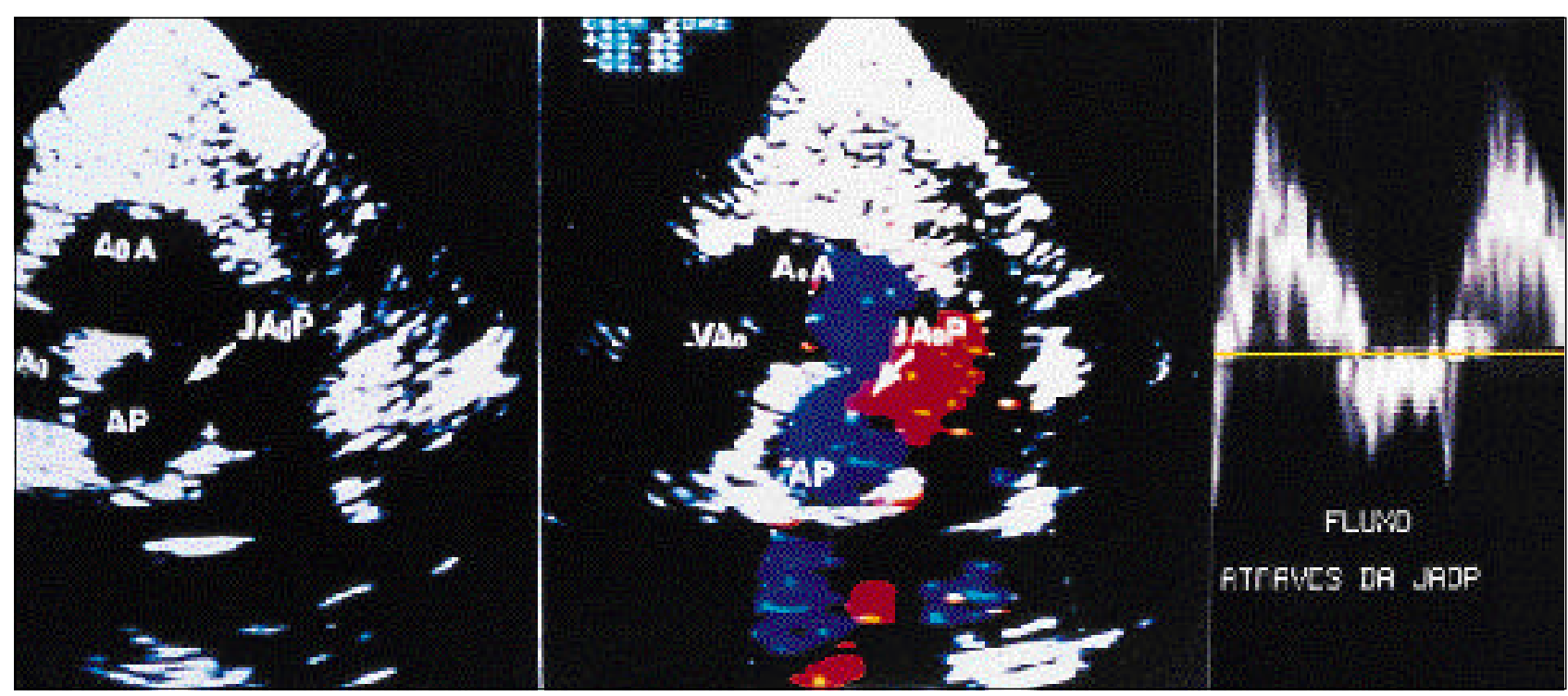

Fig. 3 - Suprasternal plane showing the longitudinal axis of the aortic arch: A) Two-dimensional image shows the proximal communication between the ascending aorta and the pulmonary trunk (type I APW); B) bidirectional flow by color Doppler: red flow from the aorta to the pulmonary artery, blue flow in the opposite direction; C) Doppler diastolic reversal flow from the ascending aorta to the pulmonary artery. AoA- ascending aorta; AP- pulmonary artery; JAOP-aortopulmonary window; VAo- aortic valve. 

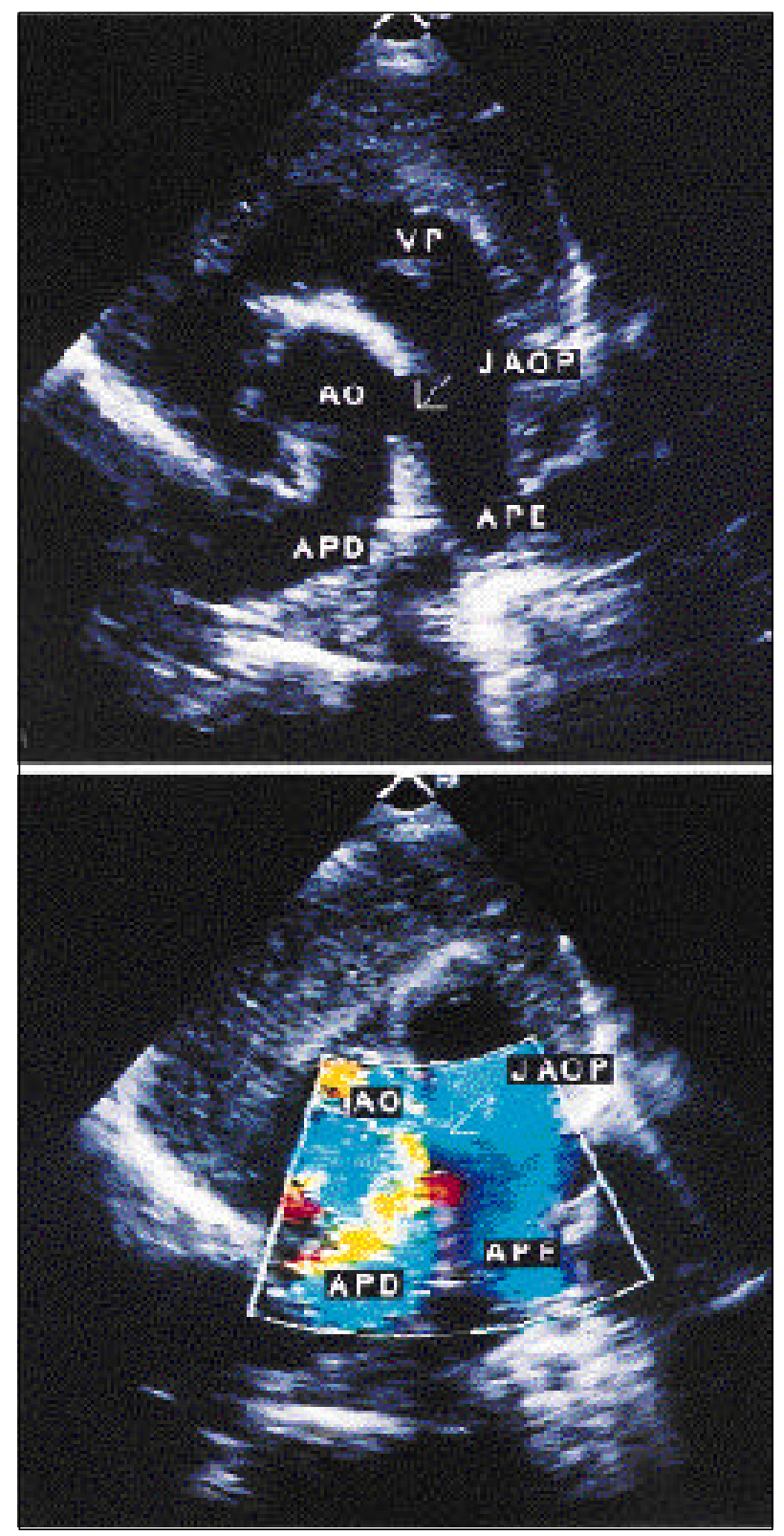

Fig. 4 - High parasternal short axis plane: A) two-dimensional image: the distal communication between the ascending aorta and the right pulmonary artery and the normal continuity between the pulmonary trunk and the left pulmonary artery are visualized. B) Color flow mapping showing the delineation of the arterial communication. AO- aorta; VP- pulmonary valve; JAOP- aortopulmonary window; APD- right pulmonary artery; APE- left pulmonary artery.

Right after APW closure at surgery, there was a sudden fall in the pulmonary pressure when the defect was an isolated one. Plicature of the mitral ring was necessary in two patients with isolated APW. In a patient with TF and pulmonary valve atresia associated with APW, Rastelli's procedure was performed, with an extracardiac conduit implantation between the right ventricle and the pulmonary arteries, together with a ventricular septalplasty. In a patient with DORV and a non-committed VSD, a tunnel from the left ventricle (LV) to the pulmonary trunk was created after enlargement of the existing VSD. Senning procedure, resection of a mitral supravalvar membrane and re-implantation of the left subclavian artery were also performed in this patient. An LV-Aorta tunnel and a ventricular septalplasty were performed in a patient with DORV and subaortic VSD.

In the child who had anomalous origin of the right coronary artery from the pulmonary artery, enlargement of the APW was performed to allow for placement of the bovine pericardium patch in a position to set the right coronary artery connected to the aorta. A subaortic fibrous ring was resected and a posterior annuloplasty of the mitral valve was performed using a bovis pericardium patch. Effective resection of the left ventricular outflow tract was also performed in an adolescent with subaortic stenosis.

The newborn with APW, aortic valve atresia, interruption of the aortic arch and a muscular VSD in the LV outflow tract was in renal failure and in anasarca when he was sent to surgery and ended up dying intraoperatively, after banding of the pulmonary artery, interposition of the left carotid artery in the descending aorta and placement of a conduit between the ascending and descending aorta.

In the infant with coarctation of the aorta and a PDA, it was necessary to enlarge a hypoplastic aortic arch with a bovine pericardium patch, section and suture of a large PDA, measuring $6 \mathrm{~mm}$ in diameter.

In the child with APW and a VSD, both defects were closed with bovis pericardium patches.

Clinical and Surgical Evolution: Six patients with isolated APW were discharged 8 days after surgery. The

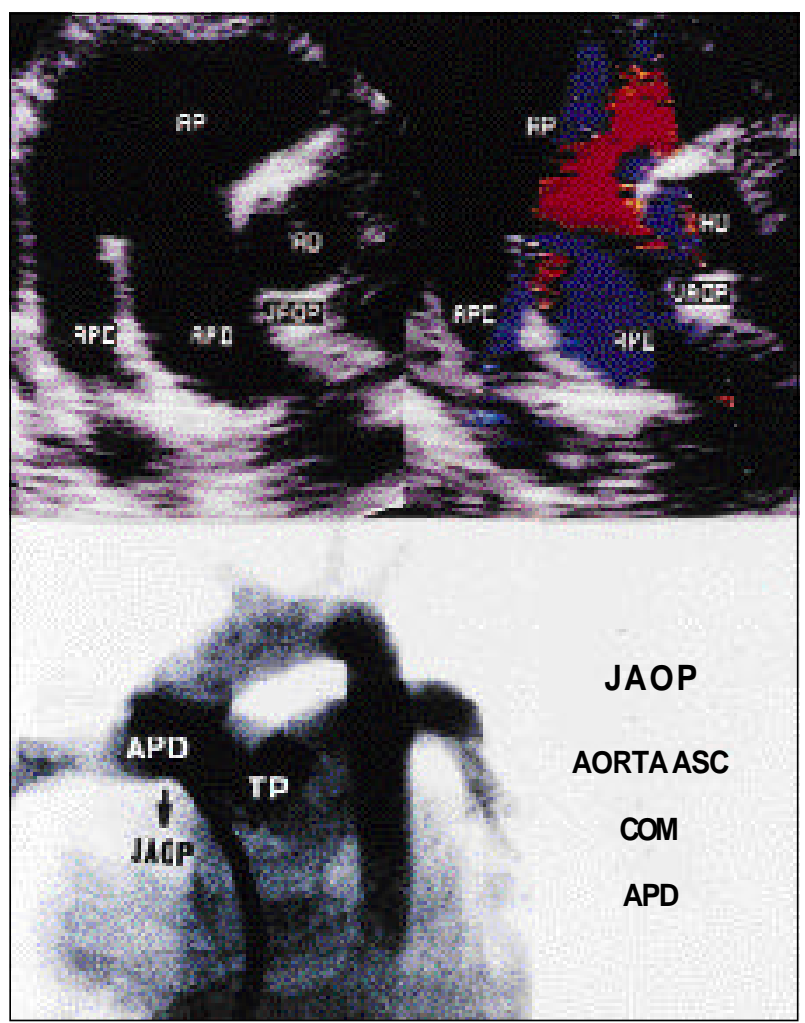

Fig. 5 - Correlation between the echocardiogram and angiogram in a case of type II aortopulmonary window. AP- pulmonary artery; AO- aorta; APE- left pulmonary artery; APD- right pulmonary artery; Asc- ascending aorta; TP- pulmonary trunk; JAOP- aortopulmonary window. 


\begin{tabular}{|lcc|}
\hline \multicolumn{3}{|c|}{ Table III - Methods in the diagnosis } \\
\hline APW diagnostic methods & $\mathrm{N}$ & $\%$ \\
\hline Echocardiogram & 11 & $(61.2 \%)$ \\
Cardiac catheterization & 3 & $(16.6 \%)$ \\
Cardiac surgery & 3 & $(16.6 \%)$ \\
Necropsy & 1 & $(5.6 \%)$ \\
\hline
\end{tabular}

other seven, with associated defects, had a prolonged stay at the hospital, being discharged on the average 20 days after surgery. In the follow-up of these patients (ranging from 3 months to 12 years), all of those with isolated APW were found to be asymptomatic, while among those with associated defects, one is in NYHA class II and five are in NYHA class I (table IV).

The child who had undergone Rastelli's procedure developed obstruction of the valve conduit, and balloon dilation was performed six years after the surgery (the patient now is in NYHA class II). Five years after a Senning procedure, one patient is now in NYHA class I. Twentyeight months after surgery, the child with DORV and a VSD is asymptomatic.

The child with subaortic stenosis, severe mitral regurgitation (caused by ring dilation of the mitral valve) and anomalous RCA did well for 24 months, with reversion of atrial fibrillation to sinus rhythm 60 days after surgery. Another adolescent who had undergone subaortic fibrous ring resection also did well, without significant gradient in the LV outflow tract six years after surgery.

Infants who had undergone ventricular septalplasty, istmoplasty and section of the arterial ductus are also asymptomatic and have gained weight normally.

\section{Discussion}

Embryologically, APW is explained by incomplete fusion or malformation of right or left conotruncal rings between the $5^{\text {th }}$ and $8^{\text {th }}$ week of fetal life. A type I APW

\begin{tabular}{|c|c|c|c|}
\hline \multicolumn{4}{|c|}{$\begin{array}{l}\text { Table IV - Clinical and surgical aspects in the follo } \\
\text { APW or in APW with associated defects, who did }\end{array}$} \\
\hline \multicolumn{4}{|c|}{ Clinical evolution and Surgery (18 patients) } \\
\hline & Group A & & Group B \\
\hline Operated & $6(33.3 \%)$ & & $8(44.4 \%)$ \\
\hline \multirow[t]{2}{*}{ Non-operated } & $4(22.2 \%)$ & $\mid \begin{array}{l}1 \text { pre-operative d } \\
1 \text { death due to } \mathrm{HP}\end{array}$ & ------ \\
\hline & & 2 lost to FU & \\
\hline \multicolumn{2}{|l|}{$\begin{array}{l}\text { Intra-operative } \\
\text { mortality }\end{array}$} & ----- & $\begin{array}{l}1 \text { - aortic valve atresia }+ \\
\text { interruption of the aortic arch }\end{array}$ \\
\hline \multicolumn{2}{|c|}{$\begin{array}{l}\text { Late follow-up } \\
\text { ( } 3 \text { months }-12 \text { years) } \\
\text { (Operated patients) }\end{array}$} & 6 - NYHA class I & $\begin{array}{l}6 \text { - Classe funcional I } \\
1 \text { - Classe funcional II }\end{array}$ \\
\hline
\end{tabular}

occurs when the defect in the truncal septum is close to the semilunar valves; when it is more distal, a type II defect develops, while no development of the proximal and distal truncal septum leads to type III $\mathrm{APW}^{3}$. Development of the coronary arteries also occurs during the septation of the great vessels, which occasionally leads to an anomalous position of the coronary arteries ${ }^{19}$.

Type I APW is the most frequent (70\%), especially when the APW occurs as an isolated defect. Type II $(25 \%)$ is associated with other defects and type II is the rarest $(5 \%)^{20}$.

About $50 \%$ of cases of APW are associated with other defects, and this makes its diagnosis more difficult. According to the literature ${ }^{21}$, the most frequently associated anomalies are: aortic arch interruption (15-20\%), especially type A; PDA (11\%); VSD (8\%); right aortic arch (7\%); anomalies of the coronary arteries $(8 \%)$; $\mathrm{TF}(5 \%)$; subaortic stenosis (3\%); bicuspid aortic valve (3\%).

Sixty cases of aortic arch interruption had been reported up until 1997; 21 (35\%) of them occurred in association with a type II APW, 12 with a type I (20\%), 5 with a type III $(8.3 \%)$ and, in the remaining 22 cases, APW was not classified. The most common form of aortic arch interruption was type $\mathrm{A}(70 \%)$, followed by type $\mathrm{B}(15 \%)$. The incidence of type $\mathrm{C}$ interruption is not known ${ }^{22}$.

Among the 60 cases, 27 underwent surgery; 16 (59\%) died and $11(41 \%)$ survived. Among the survivors, one had undergone right pulmonary artery banding only and, in the remaining 10, the aortic arch was totally reconstructed (four with a Dacron conduit, three with an end-to-end anastomose ${ }^{23}$, two with the use of the left subclavian artery ${ }^{24}$ and one with a goro-tex conduit ${ }^{22}$ ).

The association of a distal APW, a right pulmonary artery originating from the aorta, intact ventricular septum, PDA and CoAo or interruption of the aortic arch, was reported by Berry et $\mathrm{al}^{25}$ as a rare syndrome. Until recently, 14 cases have been reported in the literature; only six underwent successful surgeries ${ }^{26}$ and three of these underwent only $1^{\text {st }}$ stage correction in the neonate period ${ }^{27}$.

The association of APW, aortic arch interruption and aortic valve atresia was reported only twice in the literature; the first reported case ${ }^{28}$ was diagnosed by necropsy and the second ${ }^{29}$ by echocardiography. Our patient in 1997 was diagnosed by echocardiography at our institution. All three patients were newborns, and all died due the severe hemodynamic compromise.

Anomalous origin of the coronary arteries can occur in 5 to $10 \%$ of the cases of APW ${ }^{30,31}$. Pre-operative diagnosis is usually difficult due to the absence of clinical manifestations of ischemia, since a high perfusion pressure secondary to the APW leads to a good coronary artery flow. The right coronary artery is the one most frequently involved (7 cases), followed by the left coronary artery ( 5 cases), single ostium coronary artery ( 2 cases) and both coronary arteries ( 1 case). These coronary artery anomalies can originate both from the APW and from the pulmonary artery itself. In the literature, an anomalous origin from the pulmonary artery was the most common (10 of 15 cases). Among these 15 cases, the diagnosis was established in the pre-opera- 
tive period in only two patients ${ }^{32}$ this makes surgical correction even more difficult, since cardiopulmonary bypass is needed ${ }^{33}$. In our study, the association of APW and anomalous origin of the coronary artery from the pulmonary artery occurred in one patient and was diagnosed during surgery.

The association of APW with TF is very rare and there have been only about 15 cases published in the literature ${ }^{34}$. The effect of the pulmonary stenosis is disguised by the left-to-right shunt at the level of the great vessels, with reduction of the cyanosis and the development of high pulmonary vascular resistance ${ }^{35}$. In our series, the incidence of this association was $5.5 \%$. The association of APW and transposition of the great arteries is even rarer, and there are only three cases reported in the literature: the first two patients died ${ }^{36}$ and the third underwent successful anatomical correction of the transposition and closure of the APW on the $7^{\text {th }}$ day of life ${ }^{37}$.

Geva et al described the first case of APW, tricuspid valve atresia and pulmonary stenosis; pulmonary flow was established in this patient by the placement of a $3-\mathrm{mm}$ fenestrated patch in the APW ${ }^{38}$. The association of APW and pulmonary valve atresia and a VSD was reported in three other patients ${ }^{5}$. The association of APW and extracardiac anomalies has occurred occasionally in patients with Vater sequence $(0.02 \%)^{39}$. Conversely, APW has not been reported to occur in any specific syndrome.

The clinical diagnosis of APW, although difficult to make, should be considered in any patient with congestive heart failure and low weight gain ${ }^{6}$. If there is associated nonspecific mitral regurgitation, with normal mitral valve thickness and no displasia, the possibility of this diagnosis is even higher. This occurred in half of our patients with isolated $\mathrm{APW}^{6}$.

Since EKG and chest X-ray are nonspecific ${ }^{6}$, the echocardiogram is very important for diagnosing the APW, and the diagnosis depends on suspecting this lesion, the images obtained, and on the expertise of the echocardiographer ${ }^{40}$. Therefore, currently it is considered the gold standard in the diagnosis of isolated APW. In the presence of associated lesions, its accuracy decreases ${ }^{41}$. APW should always be considered when the left atrium is very dilated or there is severe pulmonary hypertension ${ }^{30}$.

The diagnosis by $2 \mathrm{DE}$ should be made by visualizing the aortopulmonary septum in two or more different planes. There should be thickening of the borders of the defect, so that drop outs that can occur on the crossing of the ascending aorta and the pulmonary artery in parasternal long and short axis views can be excluded ${ }^{41}$.

In the parasternal short axis view, the defect can be visualized between the aorta and the pulmonary artery. When the defect is large, there is bidirectional shunt by color Doppler and reverse flow in the pulmonary artery, distal to the defect ${ }^{7}$. Continuous flow by Doppler is seen only in small APW (3-4mm), when there is no significant elevation of the pulmonary artery pressure ${ }^{41}$.

In a high parasternal plane the defect can be visuali- zed. The detection of a diastolic reversal flow in the descending aorta and in the arch indicates there is left-to-right shunt in diastole through the APW ${ }^{8}$.

APW is difficult to diagnose in three situations: when the right pulmonary artery arises from the aorta ${ }^{42}$, and when there is CTA or PDA. In the first situation, the right pulmonary artery emerges isolated from the aorta ${ }^{9}$ while in APW, the right pulmonary artery is in continuity with the pulmonary trunk. CTA and APW have similar clinical and hemodynamic presentations, but there is a fundamental anatomical difference: in CTA there is just one semilunar valve, the truncal valve, while in APW and PDA, both aortic and pulmonary valvular apparatus are present ${ }^{43}$. PDA is a wellvisualized structure by $2 \mathrm{DE}$ and, usually, there is continuous flow by Doppler and on color flow mapping ${ }^{10}$.

Doppler and color flow mapping contribute greatly to the diagnosis of APW by $2 \mathrm{DE}^{8}$. After the advent of color flow mapping, the sensitivity of the echocardiogram for diagnosing the APW has increased, and the diagnostic accuracy at our institution has been $76.5 \%$ for the last five years. The necessity of performing an angiographic and hemodynamic study is now restricted to very special situations. One should be careful in indicating it, because it can be a high-risk procedure in the management of these patients ${ }^{11}$.

After the first correction by Gross (ligation), several techniques ${ }^{12}$, with or without cardiopulmonary bypass, with transaortic or transpulmonary patches, have been described.

Matsuki et al ${ }^{13}$ and Messmer ${ }^{14}$ described the use of a flap from the pulmonary artery to close the aortopulmonary defect and the use of autologous pericardium to repair the pulmonary artery. Di Bella et al reported a technique for closing the APW with a flap from the pulmonary patch but without using a patch to repair the pulmonary artery; this vessel was repaired with the use of the aorta adventitia, using the same suture. These authors described excellent results with the latter technique, where only autologous tissues with potential for normal growth, are used ${ }^{15}$.

McElhinney et al ${ }^{16}$ published a 23-year review, where 24 patients with APW underwent surgery before six months of age. Associated anomalies were present in 50\% of the cases. In the 12 patients with isolated APW who underwent surgery, there was no early or late death. In the patients with associated defects, the results were less favorable, with seven patients surviving in the long-term, all (19-79.1\%) in NYHA class I after 2 to 25 years of follow-up. In this report ${ }^{16}$, the necessity of performing an early surgery is emphasized (all patients were less than six months old at the time surgery was performed).

APW, on special occasions, can be occluded by an interventionist hemodynamic procedure. The first report of this type of occlusion was by Stamato et $\mathrm{al}^{17}$, who used a modified occlusion system consisting of two umbrellas; a mild residual shunt remained in this patient. Tulloh and Rigby ${ }^{17}$ described occlusion with the same system but without residual shunt in a six-month-old infant. Jureidini et al ${ }^{44}$ described successful closure of a 3.7-mm diameter APW in a 27-year-old woman. Interventionist hemodynamic closure should be performed in selected cases only; the defect should be well 
defined, it should be a type I defect (proximal), its dimension should range from 3 to $4 \mathrm{~mm}$, and there should be no associated anomaly of the origin of the coronary artery.

Because it is a rare congenital heart disease $(<1 \%)$ and does not have specific semiologic characteristics, APW should be considered in the differential diagnosis of children presenting with early heart failure, especially in the presence of nonspecific mitral regurgitation. Since it is associated with other defects in $50 \%$ of the cases, it should be excluded in children with other congenital heart diseases.
Missing the diagnosis may lead to death due to heart failure and pulmonary hypertension in a child who could undergo a successful surgery and become normal ${ }^{15}$. The good postoperative evolution in these patients makes the diagnosis and the indication for surgery mandatory in this situation.

\section{Acknowledgements}

We thank Dr Luiz Kajita for the hemodynamic studies and Dr Vera Aiello for the anatomopathology studies.

\section{References}

1. Elliotson J. Case of malformation of the pulmonary artery and aorta. Lancet 1830; 1: $247-51$.

2. Gross RE. Surgical closure of an aortic septal defect. Circulation 1952; 5: 858-63.

3. Mori K, Ando M, Takao A, Ishikawa S, Imai Y. Distal type of aortopulmonary window. Br Heart J. 1978; 40: 681-9.

4. Richardson JV, Doty DB, Rossi NP, Ehrenhaft JL. The spectrum of anomalies of aortopulmonary septation. J Thorac Cardiovasc Surg 1979: 78: 21-7.

5. Shore DF, Ho SY, Anderson RH, Leval M., Lincoln C. Aortopulmonary septal defect coexisting with ventricular septal defect and pulmonary atresia. Ann Thorac Surg 1983; 35: 132-7.

6. Atik E, Barbero-Marcial M, Andrade JL, et al. Exteriorização clínica de janela aortopulmonar através de insuficiência mitral por dilatação secundária do anel valvar. Arq Bras Cardiol 1994; 63: 493-5.

7. Rice MJ, Seward JD, Hagler DJ, Mair DD, Tajik AJ. Visualization of aortopulmonary window by two dimensional echocardiography. Mayo Clin Proc 1982; 57: $482-7$.

8. Horimi H, Hasegawa T, Shiraishi H, Endo H, Yanagisawa M. Detection of aortopulmonary window with ventricular septal defect by Doppler color flow imaging. Chest 1992; 101: 280-1.

9. Sreeram N, Walsh K. Aortopulmonary window with aortic origin of the right pulmonary artery. Int J Cardiol 1991; 31: 249-51.

10. Moss AJ, Adams FH. Heart disease in infants, children, and adolescents. Including The Fetus and Young Adult. $5^{\star}$ edition. Williams and Wilkins, 1995: 764-8.

11. Mendonza DA, Ueda T, Nishioka K, et al. Aortopulmonary window, aortic origin of the right pulmonary artery, and interrupted aortic arch: Detection by two-dimensional and color Doppler echocardiography in an infant. Pediatr Cardiol 1986;7:49-52.

12. Doty DB, Richardson JV, Falkousky GE, Gordonova MI, Burakovsky VI. Aortopulmonary septal defect hemodynamics, angiography, and operation. Ann Thorac Surg 1981; 32: 244-50.

13. Matsuki O, Toshikatsu Y, Yamamoto F, Nishigaki K, Uemura H, Kawashima Y. New surgical technique for total defect aortopulmonary window. Ann Thorac Surg 1992; 54: 991-2.

14. Messmer BJ. Pulmonary artery flap for closure of aortopulmonary window. Ann Thorac Surg 1994; 57: 498-501.

15. Di Bella, Gladstone DJ. Surgical management of aortopulmonary window. Ann Thorac Surg 1998; 65: 768-70.

16. McElhinney DB, Reddy M, Tworetzky W, Silverman NH, Hanley FL. Early and late results after repair of aortopulmonary septal defect and associated anomalies in infants less than 6 months of age. Am J Cardiol 1998; 81: 195-201.

17. Stamato T, Benson LN, Smallhorn JF, Freedom RM. Transcatheter closure of an aortopulmonary window with a modified double umbrella occluder system Cathet Cardiovasc Diagn 1995; 35: 165-7.

18. Tulloh RMR, Rigby ML. Transcatheter umbrella closure of aortopulmonary window. Heart 1997; 77: 479-80.

19. Lloyd TR, Marvin WJ, Lee J. Total anomalous origin of the coronary arteries from the pulmonary artery in an infant with aorticopulmonary septal defect. Pediatr Cardiol 1987; 8: 153-4.

20. Tiraboshi R, Salomone G, Crupi G, et al. Aortopulmonary window in the first year of life: Report on 11 surgical cases. Ann Thorac Surg 1988; 46: 438-41.

21. Faulkner LS, Oldham RR, Atwood GF, Graham TP. Aortopulmonary window, ventricular septal defect, and membranous pulmonary atresia with a diagnosis of truncus arteriosus. Chest 1974; 65: 351-3

22. Chiu Ing-Sh, Wang Jov-Kov, Wang M, Wang Chen-Chi. One-stage repair of aortopulmonary septal defect and interrupted aortic arch. Ann Thorac Surg 1994; 58: 1529-32.

23. Davies MJ, Dyamenahalli V, Leanage RR, Firmin RK. Total one-stage repair of aortopulmonary window and interrupted aortic arch in a neonate. Pediat Cardiol 1996, 17: 122-4.

24. Ingram MT, Ott DA. Concomitant repair of aortopulmonary window and interrupted aortic arch. Ann Thorac Surg 1992; 53: 909-11.

25. Berry TE, Bharati S, Muster AJ, et al. Distal aortopulmonary septal defect, aortic origin of the right pulmonary artery, intact ventricular septum, patent ductus arteriosus and hipoplasic of aortic istmus: a newly recognized syndrome. Am J Cardiol 1982; 49: 108-16.

26. Boonstra PW, Talsma M, Ebels T. Interruption of the aortic arch, distal aortopulmonary window, arterial duct and aortic origin of the right pulmonary artery in a neonate: report of a case succesfully repaired in an one stage operation. Int J Cardiol 1992; 34: 108-10.

27. Abbruzzese PA, Merlo M, Chiappa E, Bianco R, Ferrero F, Cappone C. Berry syndrome, a complex aortopulmonary malformation: one stage repair in a neonate. Ann Thorac Surg 1997; 64: 1167-9.

28. Rosenquist GC, Taylor JFFN, Stark J. Aortopulmonary fenestration and aortic atresia: report of an infant with ventricular septal defect, persistent ductus arteriosus, and interrupted aortic arch. Br Heart J 1974; 36: 1146-8.

29. Redington AN, Rigby ML, Ho SY, Gunthard J, Anderson HR. Aortic Atresia with aortopulmonary window and interruption of the aortic arch. Pediatr Cardiol 1991; 12: 49-51.

30. Agius PV, Rushworth A, Connolly N. Anomalous origin of left coronary artery from pulmonary artery associated with an aorto-pulmonary septal defect. $\mathrm{Br}$ Heart J 1970; 32: 708-10.

31. Brouwer MHJ, Beaufort-Krol GCM, Talsma MD. Aortopulmonary window associated with an anomalous origin of the right coronary artery. Int J Cardiol 1990; 28: 384-6.

32. D'Souza VJ, Chen MYM. Anomalous origin of coronary artery in association with aorticopulmonary window Pediatr Cardiol 1996; 17: 316-8.

33. Luisi SV, Ashraf MH, Gula G, Radley-Smith R, Yacoub M. Anomalous origin of the righ coronary artery with aortopulmonary window: functional and surgical considerations. Thorax 1980; 35: 446-8.

34. Kotari SS, Rajani M, Shrivastawa S. Tetralogy of Fallot with aortopulmonary window. Int J Cardiol 1988; 18: 105-8.

35. Carminati M, Borghi A, Valsecchi O, et al. Aortopulmonary window coexisting with tetralogy of Fallot: Echocardiographic diagnosis. Pediatr Cardiol 1990; 11: 41-3.

36. Krishnan P, Airan B, Sambamurthy MS, Shrivastava S, Rajani M, Rao IM. Complete transposition of great arteries with aortopulmonary window: Surgical treatment and embryologic significance. J Thorac Cardiovasc Surg 1991; 101: 749-51.

37. Marangi D, Peterson RJ, Ceithaml EL, Marvin WJ. Surgical repair of Dtransposition with aortopulmonary window: a case report. J Thorac Cardiovasc Surg 1996; 111: 671-2.

38. Tal G, David OA, Achi L, Argyle SJ, Martin OLP. Tricuspid atresia associated with aorto-pulmonary window: controlling pulmonary blood flow a fenestrated patch. Am Heart J 1992; 123: 260-2.

39. Kutsche LM, Lodewyk HS, Van Mierop. Anatomy and pathogenesis of aortico pulmonary septal defect. Am J Cardiol 1987; 59: 443-7.

40. Snider RA, Serwer AG, Ritter BS. Echocardiography in Pediatric Heart Disease, $2^{\mathrm{a}}$ ed. Mosby, 1997; 292-293. 
41. Balaji S, Burch M, Sullivan ID. Acuracy of cross-sectional echocardiography in diagnosis of aortopulmonary window. Am J Cardiol 1991; 67: 650-3.

42. King DH, Huhta JC, Gutgesell HP, Ott DA. Two-dimensional echocardiographic diagnosis of anomalous origin of the right pulmonary artery from the aorta: Differentiation from aortopulmonary window. J Am Coll Cardiol 1984; 4: 351-5.
43. Garver KA, Hernandez RJ, Vermilion RP, Goble MM. Correlative imaging of aortopulmonary window - demonstration with echocardiography, angiography and MRI - Circulation 1997; 96: 1036-7.

44. Jureidini SB, Spadioro JJ, Rao OS. Successful transcatheter closure with the buttored device of aortopulmonary window in an adult. Am J Cardiol 1998; 81: 371-2. 